OPEN ACCESS

Edited by:

Michael Harrison Hsieh, Children's National Medical

Center, USA

Reviewed by:

Willem Hanekom,

Gates Foundation, USA

Andrew DiNardo,

Baylor College of Medicine, USA

${ }^{*}$ Correspondence:

Laura E. Savolainen

laura.e.savolainen@helsinki.fi

Specialty section:

This article was submitted to

Microbial Immunology,

a section of the journal

Frontiers in Immunology

Received: 07 March 2016 Accepted: 03 June 2016

Published: 14 June 2016

Citation:

Savolainen LE, Kantele A, Knuuttila A Pusa $L$, Karttunen $R$, Valleala $H$ and

Tuuminen T (2016) Combined Expression of IFN- $\gamma, \mathrm{IL}-17$, and IL-4 mRNA by Recall PBMCs Moderately

Discriminates Active Tuberculosis from Latent Mycobacterium tuberculosis Infection in Patients with Miscellaneous Inflammatory Underlying Conditions.

Front. Immunol. 7:239. doi: 10.3389/fimmu.2016.00239

\section{Combined Expression of IFN- $\gamma$, IL-17, and IL-4 mRNA by Recall PBMCs Moderately Discriminates Active Tuberculosis from Latent Mycobacterium tuberculosis Infection in Patients with Miscellaneous Inflammatory Underlying Conditions}

\author{
Laura E. Savolainen ${ }^{1 *}$, Anu Kantele ${ }^{1,2,3}$, Aija Knuuttila4, Liana Pusa ${ }^{5}$, Riitta Karttunen ${ }^{1,6}$, \\ Heikki Valleala ${ }^{7}$ and Tamara Tuuminen ${ }^{1,8}$
}

\begin{abstract}
${ }^{1}$ Department of Bacteriology and Immunology, Haartman Institute, University of Helsinki, Helsinki, Finland, ${ }^{2}$ Department of Medicine, Division of Infectious Diseases, Helsinki University Central Hospital, Helsinki, Finland, ${ }^{3}$ Department of Medicine, Institute of Clinical Medicine, University of Helsinki, Helsinki, Finland, ${ }^{4}$ Heart and Lung Center, Helsinki University Central Hospital, Helsinki, Finland, ${ }^{5}$ Länsi-Uusimaa Hospital, Tammisaari, Finland, ${ }^{6}$ Laboratory Division (HUSLAB), Helsinki University Central Hospital, Helsinki, Finland, ' Department of Medicine, Division of Rheumatology, Helsinki University Central Hospital, Helsinki, Finland, ${ }^{8}$ Eastern Finland Laboratory Centre Joint Authority Enterprise, Mikkeli, Finland
\end{abstract}

New biomarkers are needed for discriminating active tuberculosis (TB) from latent TB infection (LTBI), especially in vulnerable groups representing the major diagnostic challenge. This pilot study was carried out to explore the diagnostic potential of selected genes, IFN- $\gamma, I L-17, I L-4$, and FoxP3, associated with TB immunity and immunopathology. IFN- $\gamma, \mathrm{IL}-17, \mathrm{IL}-4$, and FoxP3 mRNA expression levels were measured by quantitative reverse transcription PCR (RT-qPCR) from antigen-stimulated peripheral blood mononuclear cells of patients with active TB $(n=25)$; patients with miscellaneous inflammatory disorders and concomitant LTBI $(n=20)$, rheumatoid arthritis (RA) being the most predominant in the group $(n=11)$; and in healthy Bacillus Calmette-Guérin (BCG) vaccinees $(n=8)$. While the levels of FoxP3 mRNA did not differ between the tested groups, the cumulative expression levels of purified protein derivative-stimulated IFN- $\gamma, \mathrm{IL}-17$, and IL-4 mRNAs were found to distinguish active TB from the whole group of LTBI with $48 \%$ sensitivity and $85 \%$ specificity. When restricting the LTBI group to RA cases only, the sensitivity was $56 \%$ and specificity $100 \%$. When interpreting the result as positive in at least one of the mRNAs IFN- $\gamma$, IL-17, or IL-4, sensitivity of $64 \%$ and specificities of $75 \%$ (heterogeneous group of LTBI) or $100 \%$ (LTBI with RA) were achieved. Moderate discrimination of active TB from LTBI with miscellaneous inflammatory underlying conditions by using combined quantitative expression of IFN- $\gamma, \mathrm{IL}-17$, and IL-4 mRNA seems not to be of high diagnostic potential.

Keywords: IFN- $\gamma$, IL-17, IL-4, mRNA, active TB, LTBI 


\section{INTRODUCTION}

T cell-mediated immunity through the Th1-arm of the immunologic system serves an important function in controlling tuberculosis (TB). Almost everyone infected with Mycobacterium tuberculosis $(M t b)$ produces IFN- $\gamma$ and TNF- $\alpha$, yet these cytokines cannot confer protection against clinical disease (1).

T cell-based IFN- $\gamma$ release assays (IGRAs) developed a decade ago are the first diagnostic tests conceived after the century-old tuberculin skin test for identification of contact with $M t b$ (2). Although not capable of discriminating active TB from latent TB infection (LTBI), IGRAs are used in areas with low TB incidence as a supplemental method in subjects with symptoms suggestive of TB. A negative IGRA test in an immunocompetent patient indicates that active TB is improbable. (3) From the diagnostic point of view, patients with miscellaneous inflammatory musculoskeletal disorders responding poorly to conventional therapy present a great diagnostic challenge. In these patients, LTBI should be excluded before the commencement of the so-called biological therapy with, e.g., TNF- $\alpha$ blockers, due to the risk of TB reactivation (4).

The diagnostic potential of $\mathrm{T}$ cell subsets other than Th1 and its markers is not yet fully exploited. For example, the recently described Th17 subset (5) producing proinflammatory cytokine IL-17 promotes chemokine expression and the recruitment of neutrophils and stimulates T cells producing IFN- $\gamma$ in the lungs. This cytokine is important in early granuloma formation, i.e., the protective mechanism to wall off an infection (6). However, when neutrophil recruitment gets too extensive and IL-17 is secreted in excess, the fine balance is shifted to "overwhelmed" immune response, resulting in tissue damage and necrosis inside the granuloma (7).

Regulatory $\mathrm{T}$ cells (Tregs) expressing the forkhead box P3 (FoxP3) serve to limit the effector response to the infectious agent, which may result in a failure of infection control. These cells have proved to minimize tissue damage and immunopathological effects caused by effector mechanisms. (8) For example, in a murine model of TB, Tregs delayed the recruitment of $M t b$-specific effector T cells to the lungs, thus impairing immune protection (9). Indeed, higher levels of Tregs in peripheral blood and the lungs of patients with active TB compared to healthy controls were described $(10,11)$.

Th2 cells have a distinct role in the pathogenesis of TB. The excessive production of IL-4 may attenuate the Th1 response and lead to severe immunopathological consequences (12). Elevated levels of IL-4 mRNA have been detected from peripheral blood mononuclear cells (PBMCs) of patients with active TB (13) and those LTBI alike (14). On the other hand, IL-482, which is an antagonist of IL-4 and a truncated variant of IL-4, has proved elevated in LTBI and in cured TB $(13,15,16)$. The ratio of IL-4 to IL-482 has been suggested to function as a reliable marker of treatment efficacy $(13,16)$.

This study was undertaken to explore the diagnostic value of IFN- $\gamma, I L-4, I L-17$, and FoxP3 gene expression levels. We set out to investigate whether the quantitative expression of these biomarkers differs between groups with active $\mathrm{TB}$ and LTBI.

\section{MATERIALS AND METHODS}

\section{Ethical Statements}

The study protocol was approved by the Southwest Finland district Ethical Committee (DroNo 47/180/2009) and by Helsinki and Uusimaa Hospital district (149/2010). All patients provided written informed consent.

\section{Study Subjects}

Nine milliliters of whole heparinized blood was collected from 25 patients with active TB group, 20 with LTBI (LTBI group), and 8 healthy volunteers with a history of Bacillus Calmette-Guérin vaccination in their childhood (BCG group). Subjects with LTBI were further subdivided. The rheumatoid arthritis (RA) subgroup included the patients with RA $(n=11)$. The MISC subgroup $(n=9)$ includes the patients with miscellaneous inflammatory conditions (one of each: vasculitis, ankylosing spondylitis, myiasis, mycoplasma infection, streptococcal skin infection, unknown skin infection, tonsillitis, COPD, and weakness of skin sensation). IGRA tests were performed as a diagnostic work-up in LTBI group, and active TB was excluded in all. In the TB group, 22 patients had been diagnosed with pulmonary TB and 3 with extrapulmonary TB. Only one pulmonary TB patient was diagnosed on the basis of clinical presentation, radiological findings consistent with TB, and a good response to anti-TB treatment. All other TB patients were diagnosed by $M t b$ isolation. The blood samples of all TB patients were drawn not more than 2 weeks after initiation of antiTB treatment (median: 7 days, range: 0-14 days). LTBI diagnosis was composed on the basis of a positive IGRA result and a history of TB exposure, with neither radiological nor clinical signs of active TB. In the BCG group, LTBI was excluded by negative IGRA result. The demographic and clinical characteristics of the study subjects are presented in Table 1. Previous treatment schemes for RA are shown in Table 2. All enrolled patients and healthy subjects were HIV negative.

\section{Quantitative Reverse Transcription PCR}

Peripheral blood mononuclear cells were isolated with Ficoll paque (Amersham Biosciences AB, Uppsala, Sweden) centrifugation and stored in liquid nitrogen until use or stimulated immediately. A total of the cells were incubated in RPMI-10\% FCS (Sigma-Aldrich, Saint Louis, MO, USA) with purified protein derivative (PPD) [Statens serum institute (SSI)] $(10 \mu \mathrm{g} / \mathrm{ml})$, pool of culture filtrate protein 10 (CFP-10), and early secretory antigenic target (ESAT-6) peptides (Oxford Immunotec, Oxford, $\mathrm{UK})$ and without antigen for $22 \mathrm{~h}(17,18)$ at $37^{\circ} \mathrm{C}, 5 \% \mathrm{CO}^{2}$ and lysed with TRI Reagent (Molecular research center, Inc., Cincinnati, OH, USA). mRNA was extracted with RNeasy mini kit (Qiagen, Dusseldorf, Germany) according to manufacturer's instructions and transcribed using AMV reverse transcriptase (New England Biolabs, Ipswich, England), Oligo $(\mathrm{dT})_{23}$ primers (Sigma-Aldrich), and dNTP Mix (Thermo Scientific, Waltham, MA, USA) in a final volume of $20 \mu$ l. RiboLock RNase Inhibitor was used (thermo scientific). Amplification was performed in a total volume of $20 \mu \mathrm{l}$ using the Power SYBR Green PCR Master Mix (Life Technologies Ltd., Paisley, UK) as instructed. The validated (19) housekeeping gene, human ribosomal protein (HuPO), 
TABLE 1 | Clinical and demographical data of enrolled subjects.

\begin{tabular}{|c|c|c|c|c|c|c|}
\hline Patient groups & $n$ & Age range (mean) & Female $(n) \%$ & AFB pos. (n) \% & Culture pos $(n) \%$ & IGRA pos $(n) \%$ \\
\hline Active TB (TB) & 25 & $24-87(44)$ & $10(40)$ & $19(76)$ & $24(96)$ & $\mathrm{n} / \mathrm{d}$ \\
\hline Active TB, pulmonary (TB) & 22 & $26-87(45)$ & $8(36)$ & $19(86)$ & $21(95)$ & $\mathrm{n} / \mathrm{d}$ \\
\hline Active TB, extrapulmonary (TB) & 3 & 24-61 (36) & $2(67)$ & $0(0)$ & $3(100)$ & $\mathrm{n} / \mathrm{d}$ \\
\hline Latently infected (LTBI) & 20 & $34-77(61)$ & $10(50)$ & $n / d$ & $n / d$ & $20(100)$ \\
\hline Rheumatic diseases ${ }^{a}$ & 13 & 49-77 (65) & $8(62)$ & $n / d$ & $n / d$ & $13(100)$ \\
\hline Miscellaneous conditions ${ }^{b}$ & 7 & $34-64(56)$ & $2(29)$ & $n / d$ & $n / d$ & $7(100)$ \\
\hline Healthy BCG vaccinees (BCG) & 8 & $25-50(34)$ & $6(75)$ & $n / d$ & $n / d$ & $0(0)$ \\
\hline
\end{tabular}

$n / d$, not defined.

${ }^{a} R A$, rheumatic arthritis $(n=10) ; J R A$, juvenile rheumatic arthritis $(n=1)$, vasculitis $(n=1), \operatorname{SPA}$ ankylosing spondylitis $(n=1)$.

bInfection other than TB $(n=5), \operatorname{COPD}(n=1)$, weakness of skin sensation $(n=1)$.

TABLE 2 | Characteristics of LTBI patients with a rheumatic disease.

\begin{tabular}{|c|c|c|c|c|c|c|c|}
\hline Gender & Diagnosis & $\begin{array}{c}\text { Disease } \\
\text { duration (years) }\end{array}$ & $\begin{array}{l}\text { Biological } \\
\text { medicine (months) }\end{array}$ & $\begin{array}{c}\text { Prednisone } \\
\text { dose (mg/day) }\end{array}$ & DMARDs $^{a}$ & $\mathrm{CRP}^{\mathrm{b}} \mathrm{mg} / \mathrm{l}$ & $\begin{array}{l}\mathrm{ESR}^{\mathrm{c}} \\
\mathrm{mm} / \mathrm{h}\end{array}$ \\
\hline M & $\mathrm{RA}^{\mathrm{d}}(\mathrm{M} 05.8)$ & 26 & Etanercept (32) & 5 & $\mathrm{Mtx}^{\ominus}, \mathrm{SASP}^{\mathrm{f}}$, and HCQ ${ }^{\mathrm{g}}$ & 3 & 17 \\
\hline $\mathrm{F}$ & RA (M06.0) & 28 & Etanercept (59) & 5 & - & 11 & 36 \\
\hline M & RA (M05.8) & 16 & $-{ }^{k}$ & 10 & Mtx & 87 & 39 \\
\hline $\mathrm{F}$ & RA (M06.0) & 9 & Etanercept (1) & - & - & 10 & 8 \\
\hline $\mathrm{F}$ & RA (M05.8) & 6 & - & 5 & Mtx, leflunomide, and HCQ & $<3$ & 2 \\
\hline $\mathrm{F}$ & RA (M05.8) & 20 & Rituximab (12) & 5 & - & 29 & 34 \\
\hline $\mathrm{F}$ & $\mathrm{JRA}^{\mathrm{h}}(\mathrm{M08.0})$ & 64 & Rituximab (23) & 7.5 & - & 18 & 13 \\
\hline $\mathrm{F}$ & RA (M05.8) & 8 & - & 5 & Leflunomide & 71 & 41 \\
\hline $\mathrm{F}$ & RA (M05.8) & 8 & - & - & SASP & 13 & 22 \\
\hline M & RA (M05.8) & 7 & Rituximab (24) & 5 & Mtx and $\mathrm{HCQ}$ & 72 & 57 \\
\hline M & Vascultis (L95.8) & 1 & - & 5 & $\mathrm{HCQ}$ & 7 & 5 \\
\hline M & RA (M05.8) & 18 & - & 7.5 & Mtx and CyA & $<3$ & 26 \\
\hline $\mathrm{F}$ & SPAj (M45) & 4 & Golimumab (1) & - & Mtx and SASP & 4 & 12 \\
\hline
\end{tabular}

${ }^{a}$ Disease-modifying antirheumatic drug.

${ }^{b} \mathrm{C}$-reactive protein.

cErythrosyte sedimentation rate.

${ }^{d}$ Rheumatoid arthritis.

eMethotrexate.

${ }^{\text {fSulfasalazine. }}$

sHydroxychloroquine.

nJRA, juvenile rheumatoid arthritis.

'Cyclosporine.

iSPA ankylosing spondylitis.

kEtanercept stopped 9 months earlier (used for 21 months).

was used to normalize the mRNA values. The primers used included $H u P O$ forward, 5' -GCAATGTTGCCAGTGTCTGT- ${ }^{\prime}$, HuPO reverse, 5'-GCCTTGACCTTTTCAGCAAG-3'; IFN- $\gamma$ forward, $5^{\prime}$-ATTCGGTAACTGACTTGAATGTCC- ${ }^{\prime}, \quad I F N-\gamma$ reverse, $\quad 5^{\prime}$-CTCTTCGACCTCGAAACAGC-3' $\quad$ (20); IL-4 forward, 5'-CGA GTT GAC CGT AAC AGA CAT- $3^{\prime}, I L-4$ reverse, 5'-CGT CTT TAG CCT TTC CAA GAAG-3'; IL482 forward, 5'-CAGAGCAGAAGAACACAACTG, IL4 22 reverse, 5'-GTCTTTAGCCTTTCCAAGAAG-3' (15); IL-17 forward, 5'-GGA CTG TGA TGG TCA ACC TGA-3', IL-17 reverse, 5'-TCA TGT GGT AGT CCA CGT TCC-3' (21); FoxP3 forward, 5'-ACCTGGAAGAACGCCATC-3', FOXP3 reverse, 5'-TGTTCGTCCATCCTCCTTTC-3' (22). qPCR analysis was performed with iCycleriQ $Q^{m}$ Real-Time PCR detection system (Biorad, Hercules, CA, USA). Forty cycles were run with initial melting step of $5 \mathrm{~min}$ at $95^{\circ} \mathrm{C}$ followed by cycles of $45 \mathrm{~s}$ at $95^{\circ} \mathrm{C}$, $45 \mathrm{~s}$ at $60^{\circ} \mathrm{C}$, and $45 \mathrm{~s}$ at $72^{\circ} \mathrm{C}$. Specificity of the primers was ensured once with gel electrophoresis and later with melting curve analysis. The results were analyzed with comparative $C_{\mathrm{t}}$ method $2^{\Delta \Delta \mathrm{Ct}}(23)$.

\section{Statistical Analysis}

The data were analyzed with GraphPad Prism version 6.0 (GraphPad Software, Inc., San Diego, CA, USA.). Mann-Whitney $U$-test was used for testing the differences between the groups; $p<0.05$ was considered significant. Cutoff points with highest combined sensitivity and specificity were calculated with receiver operating-characteristic (ROC) curves and discriminative ability with area under the curves (AUCs).

\section{RESULTS}

\section{Selection of Genes for Further Evaluation}

We first tested the ability of PPD to stimulate different genes and the discriminative power of selected genes by analyzing five samples from each study group. In these pilot experiments, mRNA 
expression levels of IFN- $\gamma(p=0.095)$, IL-17 ( $p=0.1032)$, IL-4 $(p=0.087)$, and FoxP3 $(p=0.286)$ were higher in the TB than in the LTBI group (data not shown).

\section{CFP-10 and ESAT-6 Peptide Pools As Gene Expression Stimulators}

mRNA expression levels of IFN- $\gamma$, IL-17, IL-4, and FoxP3 were analyzed after stimulation with a pool of peptides derived from CFP-10 and ESAT-6. Peptides stimulated IFN- $\gamma$ and IL-4 mRNA expression, but difference was not observed between the medians of the IFN- $\gamma$ expression in the TB and the LTBI groups (Figure 1). In the TB group, the median of IL-4 mRNA expression appeared higher than that in the LTBI group, yet the difference did not prove statistically significant (Figure 1). The peptide antigen stimulation resulted in the expression of IL-4 mRNA in two LTBI patients also, and those were diagnosed with RA more than 20 years ago. Both patients received biological treatment during our investigation. As expected, neither IFN- $\gamma$ nor IL-4 mRNA expression levels were found elevated in the BCG group (Figure 1). Peptide stimulation induced neither FoxP3 nor IL-17 expressions in any of the study groups (data not shown).

\section{Testing of Different Combinations of Selected Genes As Potential Biomarkers to Differentiate Active TB from LTBI}

For the final assessment, $I F N-\gamma, I L-17, I L-4$, and FoxP3 genes and PPD stimulation were selected. Altogether 25, 20, and 8 samples from TB, LTBI, and BCG groups were analyzed, respectively. A comparison of the FoxP3 gene expression between the TB and LTBI groups showed highly overlapping levels and no differences in the medians (data not shown). After PPD stimulation, in the TB group, the IFN- $\gamma$, IL-17, and IL-4 mRNA expression levels were higher than in the LTBI group (Figures 2A-C), yet these differences did not prove statistically significant (Table 3 ). The cutoff levels for the IFN- $\gamma$, IL-17, and IL-4 assays to discriminate the TB from the LTBI group were assessed with ROC curve and AUC analyses (Figures 2A-C; Table 3). The cutoffs were set at the levels with at least $85 \%$ specificity. In the BCG group, two subjects reacted over the cutoff in the IFN- $\gamma$ expression assay, but none in the IL-17 or IL-4 expression. Altogether, 11/25, 8/25, and 8/25 subject from the TB group and $3 / 20,2 / 20$, and $2 / 20$ from the LTBI groups produced positive results for the IFN- $\gamma$, IL-17, and IL-4 expression levels, respectively. Next, the discriminative ability of the cumulative expression of IFN- $\gamma$, IL-17, and IL- 4 was analyzed (Table 3). No statistically significant differences between the groups were observed with any of the combinations tested. However, a sensitivity of $48 \%$ and a specificity of $85 \%$ were achieved when calculating the cumulative expression of IFN- $\gamma$, IL-17, and IL-4 or IFN- $\gamma$ and IL-17 mRNAs (Table 3). Alternatively, any positive result in at least one test of IFN- $\gamma$, IL-17, or IL-4 resulted in a sensitivity of $64 \%$ and a specificity of $75 \%$. Positive results in at least in IFN- $\gamma$ or IL- 4 produced a sensitivity of $60 \%$ and the specificity of $80 \%$. The results of all the tested combinations are shown in Table 3.

\section{Various Combinations of Selected Genes As Potential Biomarkers to Differentiate Active TB from LTBI in Patients with RA or with Miscellaneous Inflammatory Conditions}

Quantitative expression of IFN- $\gamma$, IL-17, and IL-4 mRNAs to differentiate active TB from LTBI in an RA or MISC groups was investigated. A significant difference in IFN- $\gamma(p<0.05)$ and IL-4 $(p<0.05)$ mRNA expression levels was found between the TB and the RA groups (Figures 3A-C; Table 4). In IL-17 mRNA analysis, the difference between TB and RA groups was not statistically significant $(p=0.264)$, yet there was a positive trend toward discrimination (Table 4). When the MISC and the TB group were compared, neither the differences in the cytokine levels or their combinations reached statistical significance (Table 4). In the MISC group, the highest IFN- $\gamma$ mRNA expression levels were found in patients with tonsillitis and unknown skin infection. IL-17 mRNA expression levels were increased in patients with myiasis and ankylosing spondylitis, and IL-4 in patients with vasculitis and unknown skin infection.
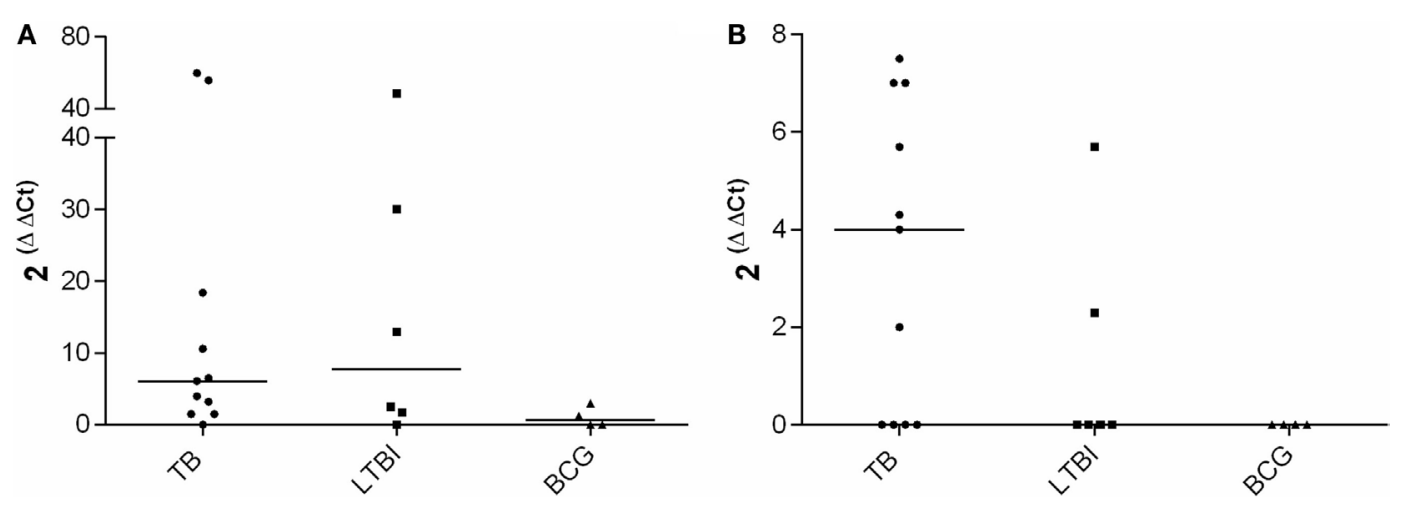

FIGURE 1 | CFP-10-ESAT-6 peptide pool stimulated mRNA expression. Fold increase in IFN- $\gamma(\mathbf{A})$ and IL-4 (B) expression in TB $(n=11)$, LTBI $(n=6)$ and $\operatorname{BCG}(n=4)$ groups. Medians of the groups are shown with horizontal bars. 

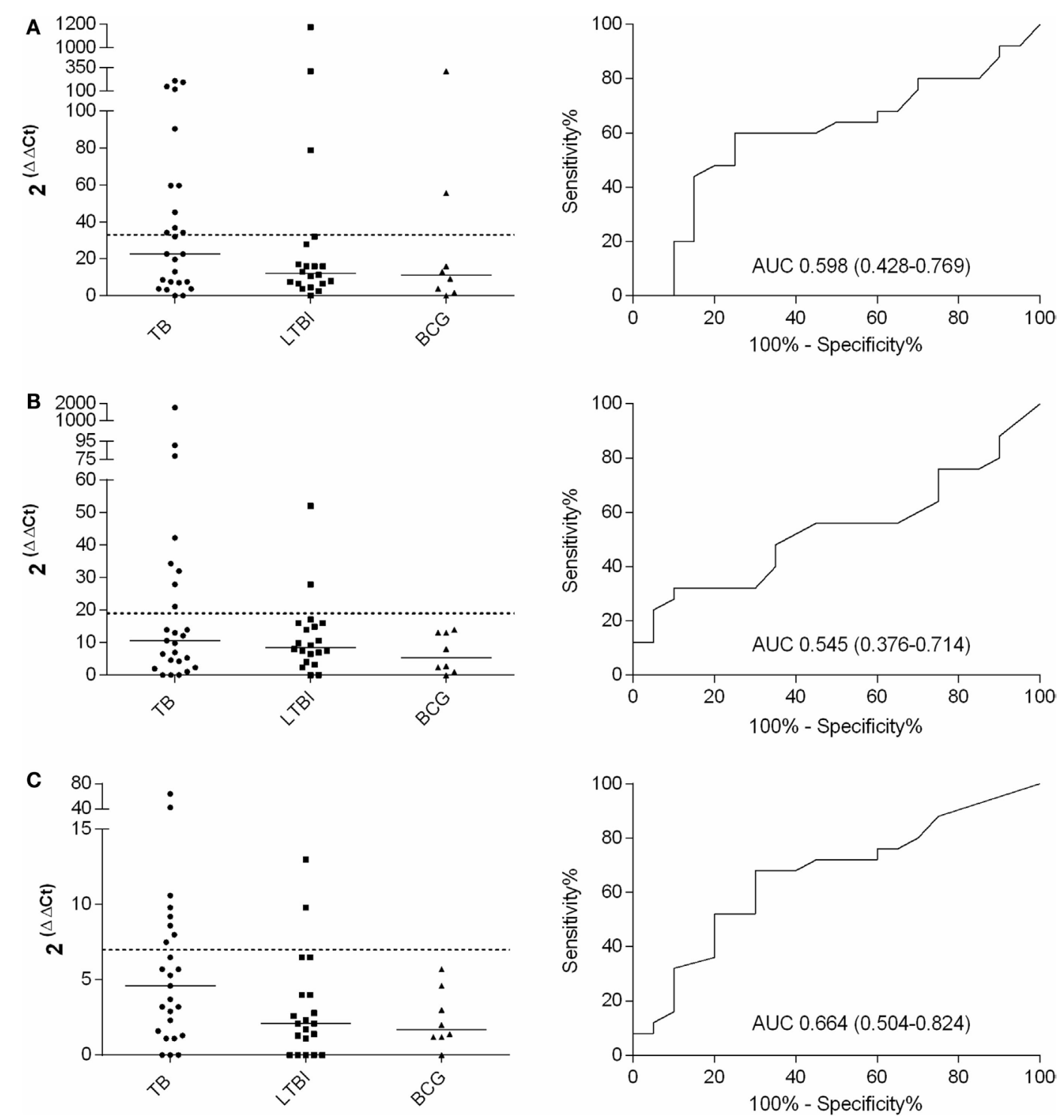

FIGURE 2 | Fold increases in IFN- $\gamma$ (A), IL-17 (B), and IL-4 (C) mRNA expression after PPD stimulation and the respective ROC curves with AUCs (CI 95\%). TB, $n=25$; LTBI, $n=20$; and BCG, $n=8$. The cutoff values for each assay are shown with dashed lines and the medians of the gene expression levels for each group with horizontal bars.

TABLE 3 | Cytokine gene expression levels and their combinations measured from PPD-stimulated PBMCs to discriminate patients with active TB from LTBI.

\begin{tabular}{|c|c|c|c|c|c|c|}
\hline Cytokine combination & $\begin{array}{c}\text { Positive active } \\
\text { TB }(n=25)\end{array}$ & $\begin{array}{l}\text { Positive LTBI } \\
(n=20)\end{array}$ & $\begin{array}{l}\text { Sens. } \\
(\%)\end{array}$ & $\begin{array}{l}\text { Spec. } \\
(\%)\end{array}$ & $\begin{array}{c}\text { AUC } \\
\text { (CI 95\%) }\end{array}$ & $p$ \\
\hline $\mathrm{IFN}-\gamma$ & 11 & 3 & 44 & 85 & $0.598(0.426-0.770)$ & 0.263 \\
\hline IL-17 & 8 & 2 & 32 & 90 & $0.534(0.363-0.705)$ & 0.698 \\
\hline IL-4 & 8 & 2 & 32 & 90 & $0.662(0.500-0.824)$ & 0.064 \\
\hline $\mathrm{IFN}-\gamma+\mathrm{IL}-17+\mathrm{IL}-4$ & 12 & 3 & 48 & 85 & $0.586(0.414-0.758)$ & 0.326 \\
\hline $\mathrm{IFN}-\gamma+\mathrm{IL}-17$ & 12 & 3 & 48 & 85 & $0.551(0.376-0.726)$ & 0.560 \\
\hline $\mathrm{IFN}-\gamma+\mathrm{IL}-4$ & 9 & 3 & 36 & 80 & $0.623(0.452-0.794)$ & 0.160 \\
\hline $\mathrm{IL} 4+\mathrm{IL}-17$ & 11 & 3 & 44 & 85 & $0.594(0.426-0.762)$ & 0.283 \\
\hline IFN- $\gamma$ or IL-17 or IL-4 & 16 & 5 & 64 & 75 & $\mathrm{n} / \mathrm{a}$ & $\mathrm{n} / \mathrm{a}$ \\
\hline IFN- $\gamma$ or IL-17 & 13 & 4 & 52 & 80 & $\mathrm{n} / \mathrm{a}$ & $\mathrm{n} / \mathrm{a}$ \\
\hline IFN- $\gamma$ or IL-4 & 15 & 4 & 60 & 80 & $\mathrm{n} / \mathrm{a}$ & $\mathrm{n} / \mathrm{a}$ \\
\hline IL-17 or IL-4 & 12 & 4 & 48 & 80 & $\mathrm{n} / \mathrm{a}$ & $\mathrm{n} / \mathrm{a}$ \\
\hline
\end{tabular}



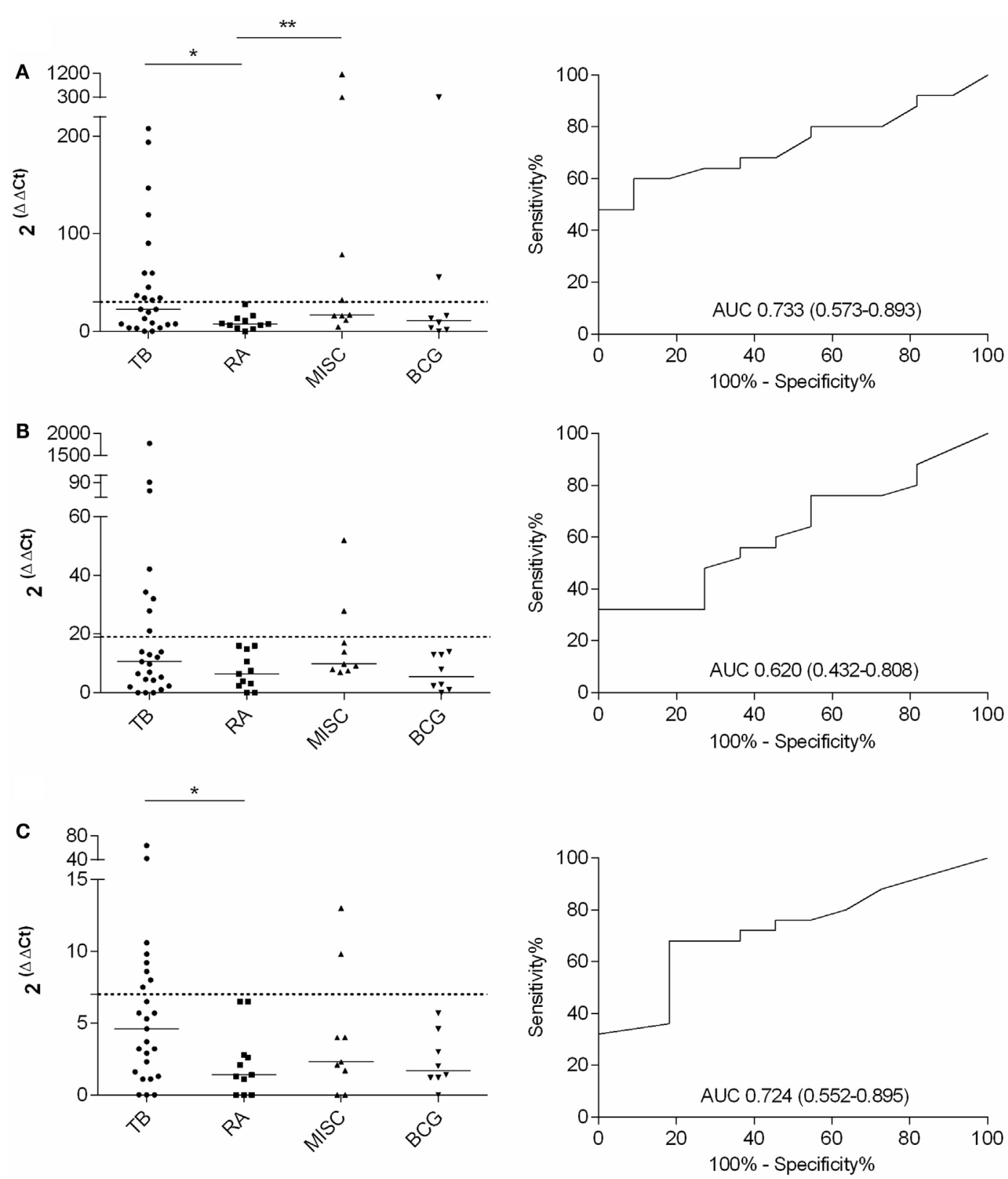

FIGURE 3 | Fold increase in IFN- $\gamma$, IL-17, and IL-4 mRNA expression after PPD stimulation and the respective ROC curves with AUCs (CI 95\%) calculated with TB and RA groups. TB, $n=25$; RA, $n=11$; MISC, $n=9$; and BCG, $n=8$. (A) IFN- $\gamma$, (B) IL-17, and (C) IL-4. Dashed lines represent the cutoff for each assay and the horizontal bars represent the medians of the gene expression level for each group.

The ROC curves with AUCs for the IFN- $\gamma$, IL-17, and IL-4 mRNA assays were constructed with the TB and RA groups, and the cutoffs were assessed to such a level where all the patients in the RA group remained below the cutoff line (Figure 3 ). With this approach, 48,32 , and $32 \%$ sensitivities were achieved in IFN- $\gamma$, IL-17, and IL-4 assays, respectively, for TB and RA groups. When the cumulative mRNA expressions were calculated, improved sensitivity up to $56 \%$ was found in most of the combinations (Table 4). Finally, the analysis of any positive result in at least one of the tests of IFN- $\gamma$, IL-17, or IL-4 resulted in the sensitivity of $64 \%$ with $100 \%$ specificity.

\section{DISCUSSION}

Distinguishing active TB from LTBI, particularly, in patients with underlying inflammatory conditions that may resemble the clinical presentation of $\mathrm{TB}$, remains an important clinical challenge. It is especially demanding in patients with a history of potential 
TABLE 4 | Cytokine gene expression levels and their combinations measured from PPD-stimulated PBMCs to discriminate patients with active TB from LTBI with RA.

\begin{tabular}{|c|c|c|c|c|c|c|}
\hline $\begin{array}{l}\text { Cytokine } \\
\text { combination }\end{array}$ & $\begin{array}{c}\text { Positive Active } \\
\text { TB }(n=25)\end{array}$ & $\begin{array}{l}\text { Positive LTBI + RA } \\
(n=11)\end{array}$ & $\begin{array}{l}\text { Sens. } \\
(\%)\end{array}$ & $\begin{array}{l}\text { Spec. } \\
(\%)\end{array}$ & $\begin{array}{c}\text { AUC } \\
\text { (CI 95\%) }\end{array}$ & $p$ \\
\hline IFN- $\gamma$ & 12 & 0 & 48 & 100 & $0.733(0.573-0.893)$ & $<0.05^{\star}$ \\
\hline $\mathrm{IL}-17$ & 8 & 0 & 32 & 100 & $0.620(0.432-0.808)$ & 0.264 \\
\hline IL-4 & 8 & 0 & 32 & 100 & $0.724(0.552-0.895)$ & $<0.05^{\star}$ \\
\hline $\mathrm{IFN}-\gamma+\mathrm{IL}-17+\mathrm{IL}-4$ & 14 & 0 & 56 & 100 & $0.720(0.556-0.884)$ & $<0.05^{\star}$ \\
\hline $\mathrm{IFN}-\gamma+\mathrm{IL}-17$ & 14 & 0 & 56 & 100 & $0.675(0.501-0.848)$ & 0.102 \\
\hline $\mathrm{IFN}-\gamma+\mathrm{IL}-4$ & 14 & 0 & 56 & 100 & $0.758(0.603-0.914)$ & $<0.05^{\star}$ \\
\hline $\mathrm{IL}-4+\mathrm{IL}-17$ & 11 & 0 & 44 & 100 & $0.693(0.518-0.867)$ & 0.069 \\
\hline IFN- $\gamma$ or IL-17 or IL-4 & 16 & 0 & 64 & 100 & $\mathrm{n} / \mathrm{a}$ & $\mathrm{n} / \mathrm{a}$ \\
\hline IFN- $\gamma$ or IL-17 & 13 & 0 & 52 & 100 & $\mathrm{n} / \mathrm{a}$ & $\mathrm{n} / \mathrm{a}$ \\
\hline IFN- $\gamma$ or IL-4 & 16 & 0 & 64 & 100 & $\mathrm{n} / \mathrm{a}$ & $\mathrm{n} / \mathrm{a}$ \\
\hline IL-17 or IL-4 & 12 & 0 & 48 & 100 & $\mathrm{n} / \mathrm{a}$ & $\mathrm{n} / \mathrm{a}$ \\
\hline
\end{tabular}

${ }^{*} p<0.05$ was considered significant.

exposure to TB who currently run fever of unknown cause and show elevated inflammatory markers, yet lack bacteriological confirmation of TB. Smear microscopy may not be sensitive, and culture takes too much time detecting $M t b$. Nucleic acid amplification methods, even if sensitive, are expensive and not widely available. The IGRA techniques, although applicable to ex vivo detection of sensitized T lymphocytes, are not very useful in diagnosing active TB. Furthermore, at present, biomarkers or a diagnostic test does not exist to predict disease activation in immunosuppressed individuals. Here, we present the investigation of the quantitative expressions of IFN- $\gamma$, IL-17, and IL-4, the cytokines presenting the major pathways of $\mathrm{CD}^{+}$cells differentiation after antigenic stimulus. In our study, the combined quantitative analysis of genes coding for IFN- $\gamma$, IL-17, and IL-4 proteins from the PPD-stimulated PBMCs distinguished active TB from LTBI with concomitant miscellaneous inflammatory conditions only moderately. When each cytokine was analyzed independently, the differences between the groups were not found statistically significant. The cumulative expression of IFN- $\gamma$, IL-17, and IL-4, or IFN- $\gamma$ and IL-17, resulted in $48 \%$ sensitivity with $85 \%$ specificity remaining below the desired specifications for a clinical test. Alternatively, when any of the tests for IFN- $\gamma$, IL-17, or IL-4 was over the cutoff, the assay showed a sensitivity of $64 \%$ and specificity of $75 \%$. When disease stage discriminating ability of IFN- $\gamma$, IL-17, and IL- 4 were tested with a more homogeneous LTBI group, namely the RA group, the combined analysis of IFN- $\gamma$, IL-17, and IL- 4 or IFN- $\gamma$ and IL-4 resulted in $64 \%$ sensitivity $(p<0.05)$ with $100 \%$ specificity. Thus, scrutinizing the patients groups into more homogenous ones, we were able to improve the discrimination power of the cytokine measurement. Nonetheless, we want to underline the inevitable fact that in the real clinical situation, when the diagnosis of a patient has remained unclear, the clinician is expecting to get from a laboratory a definitive interpretation regarding each individual sample, but not statistics. In our opinion, proper diagnostic method should be robust enough to categorize patients into groups. Statistical significance between the groups is in fact not sufficient to qualify any method as a diagnostic tool.
A feature that adds weight to our study is the enrollment of LTBI patients with other underlying diseases, such as rheumatoid diseases. In many previous studies $(14,16,24)$, LTBI group has been represented by household contacts (HHC). Selecting, instead, LTBI group members among subjects with underlying inflammatory conditions is expected to be more challenging from the clinical standpoint. These patients, similar to those with active $\mathrm{TB}$, have a systemic inflammatory condition, which indicates a priori a misbalanced cytokine production $(25,26)$.

The usefulness of a variety of immunological biomarkers in TB infection has been extensively investigated during last decades. The controversy regarding the applicability of any marker may partly be due to a great variety of methodologies. In some studies, cell subpopulation frequencies were measured (27), while in others cell phenotypical or functional profiles were studied (28), and yet in some others, cytokine production levels were measured with ELISA (24) or (18), like in our study, gene expression levels coding certain proteins were quantified.

One of the limitations of the study includes the relatively small cohorts of tested individuals and the great variability in the spectrum of underlying diseases in the MISC group. The degree of immunosuppression varied between the patients. However, none of the patients presented such a degree of immunosuppression that it would have prevented immunoreactivity in IGRA tests.

In many studies (including ours), the duration of anti-TB therapy in TB patients is variable, which may be a confounding factor. We attempted to standardize the duration of the anti-TB therapy by only enrolling patients having received treatment for no longer than 2 weeks (median: 7 days, range: $0-14$ days).

Limited repertoire of the tested genes is another limitation of our study, but we aimed to test only the mainstream markers of $\mathrm{T}$ cell differentiation.

In real practice, LTBI patients requiring differential diagnostics from active TB are a highly heterogenic group. Each condition within this group may present with a different degree of cytokine misbalance. LTBI group can comprise either HHC (practically healthy) or patients with RA with highly dysregulated 
cytokine and chemokine production. An additional challenge in trying to find sustainable immunological signatures lies in the nature of the TB infection, which is by no means a homogenous condition. Studies of cynomolgus macaques have shown that there is a wide spectrum of overlapping stages of infection presenting with different degrees of tissue damage and immune responses (29). According to this novel understanding, active TB is a continuum of LTBI or subclinical TB. Therefore, it appears imperative that future search for new immunological signatures be linked with the results of modern imaging tests (e.g., positron emission tomography) or other imaging techniques estimating the severity or current stage of lung pathology (30). Infection stage differentiation will most probably require simultaneous analysis of multiple markers underscoring the regulation of various genes (genomics) or protein expression profiles (proteomics) $(18,24,31)$. These findings should be linked, e.g., to the types of granulomas and the location and viability of the bacillus in different outcomes of TB.

Contrary to our findings, IFN- $\gamma$ mRNA expression levels have been reported to be significantly higher in LTBI than TB patients, when the cells are stimulated with the recombinant ESAT-6 (18). The IFN- $\gamma$ mRNA expression levels have been correlated with the production of the corresponding protein by the cells stimulated in the QuantiFeron tubes (32). In accordance with our findings, ESAT- 6 and CFP-10 protein stimulation has not proved as efficient as the PPD stimulation $(11,24,33)$. Our study showed that expression levels of the major genes associated with T-cell differentiation only moderately discriminated active TB from LTBI. As a stimulus, we used PPD for the reason that, in active TB, bacterial load is higher and, in replicating bacteria, antigen expression is more variable than, e.g., by dormant bacteria of LTBI (34). Higher variability of antigens better diversifies immune response resulting in proliferation of $\mathrm{T}$-cell clones with a wider receptor repertoire. Stimulation with PPD therefore better targets all reactive T-cell clones than, e.g., stimulation with only ESAT-6 or CFP-10.

An increased IL-17 mRNA expression has been described in mononuclear cells from pleural fluid of patients with tuberculous pleurisy (21). Compared to the healthy controls, increased IL-17 mRNA expression levels have also been found from TB patients' unstimulated PBMCs (33). In our study, antigen-stimulated IL-17 mRNA expression was associated with active TB, rather than with LTBI.

\section{REFERENCES}

1. Flynn JL, Chan J. Immunology of tuberculosis. Annu Rev Immunol (2001) 19:93-129. doi:10.1146/annurev.immunol.19.1.93

2. Pai M, Zwerling A, Menzies D. Systematic review: T-cell-based assays for the diagnosis of latent tuberculosis infection: an update. Ann Intern Med (2008) 149:177-84. doi:10.7326/0003-4819-149-3-200808050-00241

3. Lavender TW, Barrett A, Magee J, Ong EL, et al. Interferon-gamma release assays in the diagnosis of active tuberculosis disease in a low-incident setting: a 5-year review of data. Clin Microbiol Infect (2013) 19:1078-81. doi:10.1111/1469-0691.12129

4. Ramiro S, Gaujoux-Viala C, Nam JL, Smolen JS, Buch M, Gossec L, et al. Safety of synthetic and biological DMARDs: a systematic literature review
Variable expressions of IL-4 and IL $4 \delta 2$ mRNAs have been reported in the groups of active TB, LTBI, or HHCs from unstimulated cells $(13,14)$. Furthermore, the ratios of IL- 4 to IL- $4 \delta 2$ or IFN- $\gamma$ of the mRNA expression levels have been suggested as a cure indicator $(13,16)$. We also detected elevated IL-4 mRNA expression levels in patients with active TB.

The IL-4 22 gene was expressed at very low levels even after stimulation. Therefore, it was omitted from further analysis.

Rises in FoxP3 mRNA expression and expansion of Treg cells have also reported to be more common in patients with active TB than in those with the LTBI $(11,18)$. Our data did not reveal differences between the FoxP3 mRNA expression levels.

As a conclusion, we chose to explore the potential of combined quantitative expression profiling of some main markers of $\mathrm{T}$ cell activation and differentiation, IFN- $\gamma$, IL-17, and IL-4 mRNA, to discriminate between active TB and LTBI in clinical patient groups. A clinical setting is demanding as such, yet these are the patient groups representing the greatest challenge in clinical practice.

Presented results suggest that the undertaken approach seems to have only a moderate diagnostic value to qualify for routine use. Alternative approaches, probably based on pathogen-related biomarkers, should be exploited.

\section{AUTHOR CONTRIBUTIONS}

LS: designed the study, collected clinical samples, performed the analyses, interpreted the data, and wrote the first draft. AKa: collected clinical samples and applied for the ethical clearances. AKn, LP, RK, and HV: collected clinical samples. TT: designed the study, applied for the ethical clearances, and wrote the first draft. All authors contributed to the manuscript preparation, read, approved, and accepted the final version.

\section{ACKNOWLEDGMENTS}

This study was supported by the Tuberculosis Association of the University of Tampere, the Nummela Sanatorium Association, the Foundation of the Finnish Anti-Tuberculosis Association, the Research foundation of the pulmonary diseases, the Väinö and Laina Kivi Foundation, and Orion Research Foundation. We want to thank HUSLAB (Helsinki), the Department of Mycobacteriology, for help in recruiting the TB patients.

informing the 2013 update of the EULAR recommendations for management of rheumatoid arthritis. Ann Rheum Dis (2014) 73:529-35. doi:10.1136/ annrheumdis-2013-204575

5. Harrington LE, Hatton RD, Mangan PR, Turner H, Murphy TL, Murphy KM, et al. Interleukin 17-producing CD4+ effector T cells develop via a lineage distinct from the T helper type 1 and 2 lineages. Nat Immunol (2005) 6:1123-32. doi:10.1038/ni1254

6. Khader SA, Bell GK, Pearl JE, Fountain JJ, Rangel-Moreno J, Cilley GE, et al. IL-23 and IL-17 in the establishment of protective pulmonary CD4+ $\mathrm{T}$ cell responses after vaccination and during Mycobacterium tuberculosis challenge. Nat Immunol (2007) 8:369-77. doi:10.1038/ni1449

7. Torrado E, Cooper AM. IL-17 and Th17 cells in tuberculosis. Cytokine Growth Factor Rev (2010) 21:455-62. doi:10.1016/j.cytogfr.2010.10.004 
8. Belkaid Y, et al. Role of Foxp3-positive regulatory T cells during infection. Eur J Immunol (2008) 38:918-21. doi:10.1002/eji.200738120

9. Shafiani S, Tucker-Heard G, Kariyone A, Takatsu K, Urdahl KB. Pathogenspecific regulatory $\mathrm{T}$ cells delay the arrival of effector $\mathrm{T}$ cells in the lung during early tuberculosis. J Exp Med (2010) 207:1409-20. doi:10.1084/ jem.20091885

10. Guyot-Revol V, Innes JA, Hackforth S, Hinks T, Lalvani A. Regulatory $\mathrm{T}$ cells are expanded in blood and disease sites in patients with tuberculosis. Am J Respir Crit Care Med (2006) 173:803-10. doi:10.1164/ rccm.200508-1294OC

11. Marin ND, París SC, Vélez VM, Rojas CA, Rojas M, García LF. Regulatory $\mathrm{T}$ cell frequency and modulation of IFN-gamma and IL-17 in active and latent tuberculosis. Tuberculosis (Edinb) (2010) 90:252-61. doi:10.1016/j. tube.2010.05.003

12. Rook GA, Hernandez-Pando R, Dheda K, Teng Seah G. IL-4 in tuberculosis: implications for vaccine design. Trends Immunol (2004) 25:483-8. doi:10.1016/j.it.2004.06.005

13. Dheda K, Chang JS, Breen RA, Kim LU, Haddock JA, Huggett JF, et al. In vivo and in vitro studies of a novel cytokine, interleukin 4delta2, in pulmonary tuberculosis. Am J Respir Crit Care Med (2005) 172:501-8. doi:10.1164/ rccm.200502-278OC

14. Demissie A, Wassie L, Abebe M, Aseffa A, Rook G, Zumla A, et al. The 6-kilodalton early secreted antigenic target-responsive, asymptomatic contacts of tuberculosis patients express elevated levels of interleukin- 4 and reduced levels of gamma interferon. Infect Immun (2006) 74:2817-22. doi:10.1128/ IAI.74.5.2817-2822.2006

15. Demissie A, Abebe M, Aseffa A, Rook G, Fletcher H, Zumla A, et al. Healthy individuals that control a latent infection with Mycobacterium tuberculosis express high levels of Th1 cytokines and the IL-4 antagonist IL-4delta2. J Immunol (2004) 172:6938-43. doi:10.4049/jimmunol.172.11.6938

16. Wassie L, Demissie A, Aseffa A, Abebe M, Yamuah L, Tilahun H, et al. Ex vivo cytokine mRNA levels correlate with changing clinical status of ethiopian TB patients and their contacts over time. PLoS One (2008) 3:e1522. doi:10.1371/ journal.pone. 0001522

17. Lenarczyk A, Helsloot J, Farmer K, Peters L, Sturgess A, Kirkham B. Antigen-induced IL-17 response in the peripheral blood mononuclear cells (PBMC) of healthy controls. Clin Exp Immunol (2000) 122:41-8. doi:10.1046/j.1365-2249.2000.01328.x

18. Wu B, Huang C, Kato-Maeda M, Hopewell PC, Daley CL, Krensky AM, et al. Messenger RNA expression of IL-8, FOXP3, and IL-12beta differentiates latent tuberculosis infection from disease. JImmunol (2007) 178:3688-94. doi:10.4049/jimmunol.178.6.3688

19. Dheda K, Huggett JF, Bustin SA, Johnson MA, Rook G, Zumla A. Validation of housekeeping genes for normalizing RNA expression in real-time PCR. Biotechniques (2004) 37:112-9.

20. Roberts T, Beyers N, Aguirre A, Walzl G. Immunosuppression during active tuberculosis is characterized by decreased interferon-gamma production and CD25 expression with elevated forkhead box P3, transforming growth factor-beta, and interleukin-4 mRNA levels. J Infect Dis (2007) 195:870-8. doi:10.1086/511277

21. Qiao D, Yang BY, Li L, Ma JJ, Zhang XL, Lao SH, et al. ESAT-6- and CFP10 -specific Th1, Th22 and Th17 cells in tuberculous pleurisy may contribute to the local immune response against Mycobacterium tuberculosis infection. Scand JImmunol (2011) 73:330-7. doi:10.1111/j.1365-3083.2011. 02512.x
22. Burl S, Hill PC, Jeffries DJ, Holland MJ, Fox A, Lugos MD, et al. FOXP3 gene expression in a tuberculosis case contact study. Clin Exp Immunol (2007) 149:117-22. doi:10.1111/j.1365-2249.2007.03399.x

23. Schmittgen TD, Livak KJ. Analyzing real-time PCR data by the comparative C(T) method. Nat Protoc (2008) 3:1101-8. doi:10.1038/nprot.2008.73

24. Sutherland JS, de Jong BC, Jeffries DJ, Adetifa IM, Ota MO. Production of TNF-alpha, IL-12(p40) and IL-17 can discriminate between active TB disease and latent infection in a West African cohort. PLoS One (2010) 5:e12365. doi:10.1371/journal.pone. 0012365

25. Aerts NE, De Knop KJ, Leysen J, Ebo DG, Bridts CH, Weyler JJ, et al. Increased IL-17 production by peripheral $\mathrm{T}$ helper cells after tumour necrosis factor blockade in rheumatoid arthritis is accompanied by inhibition of migration-associated chemokine receptor expression. Rheumatology (Oxford) (2010) 49:2264-72. doi:10.1093/rheumatology/keq224

26. Pavlovic V, Dimic A, Milenkovic S, Krtinic D, et al. Serum levels of IL-17, IL-4, and INFgamma in Serbian patients with early rheumatoid arthritis. J Res Med Sci (2014) 19:18-22.

27. Chen X, Zhang M, Liao M, Graner MW, Wu C, Yang Q, et al. Reduced Th17 response in patients with tuberculosis correlates with IL-6R expression on CD4+ T Cells. Am J Respir Crit Care Med (2010) 7:734-42. doi:10.1164/ rccm.200909-1463OC

28. Marín ND, París SC, Rojas M, García LF. Reduced frequency of memory T cells and increased th17 responses in patients with active tuberculosis. Clin Vaccine Immunol (2012) 19:1667-76. doi:10.1128/CVI.00390-12

29. Gideon HP, Flynn JL. Latent tuberculosis: what the host "sees"? Immunol Res (2011) 50:202-12. doi:10.1007/s12026-011-8229-7

30. Barry CE III, Boshoff HI, Dartois V, Dick T, Ehrt S, Flynn J, et al. The spectrum of latent tuberculosis: rethinking the biology and intervention strategies. Nat Rev Microbiol (2009) 7:845-55. doi:10.1038/nrmicro2236

31. Lu C, Wu J, Wang H, Wang S, Diao N, Wang F, et al. Novel biomarkers distinguishing active tuberculosis from latent infection identified by gene expression profile of peripheral blood mononuclear cells. PLoS One (2011) 6:e24290. doi:10.1371/journal.pone.0024290

32. Kim S, Kim YK, Lee H, Cho JE, Kim HY, Uh Y, et al. Interferon gamma mRNA quantitative real-time polymerase chain reaction for the diagnosis of latent tuberculosis: a novel interferon gamma release assay. Diagn Microbiol Infect Dis (2013) 75:68-72. doi:10.1016/j.diagmicrobio.2012.09.015

33. Marín ND, París SC, Rojas M, García LF. Functional profile of CD4+ and CD8+ T cells in latently infected individuals and patients with active TB. Tuberculosis (Edinb) (2013) 93:155-66. doi:10.1016/j.tube.2012.12.002

34. Lin PL, Rodgers M, Smith L, Bigbee M, Myers A, Bigbee C, et al. Quantitative comparison of active and latent tuberculosis in the cynomolgus macaque model. Infect Immun (2009) 77:4631-42. doi:10.1128/IAI.00592-09

Conflict of Interest Statement: The authors declare that they have no conflict of interests. Preliminary results of this study were reported as a poster at annual meeting of Nordic Society of Clinical microbiology and Infectious Diseases, 2013.

Copyright (c) 2016 Savolainen, Kantele, Knuuttila, Pusa, Karttunen, Valleala and Tuuminen. This is an open-access article distributed under the terms of the Creative Commons Attribution License (CC BY). The use, distribution or reproduction in other forums is permitted, provided the original author(s) or licensor are credited and that the original publication in this journal is cited, in accordance with accepted academic practice. No use, distribution or reproduction is permitted which does not comply with these terms. 